\title{
Transposição ou recontextualização? Sobre a produção de saberes na educação em museus de ciências
}

\author{
Martha Marandino \\ Universidade de São Paulo, Faculdade de Educação
}

\section{Introdução}

Estudos sobre a transformação do conhecimento científico com fins de educação e divulgação têm sido realizados por vários autores no campo da educação e do ensino de ciências e de matemática em particular. Constata-se o crescimento do número de trabalhos sobre os saberes presentes nos processos educativos escolares, com o intuito de valorizar outros saberes como aqueles da experiência social e cultural, do senso comum e da prática, como fundamentais no desenvolvimento de habilidades e competências dos indivíduos (Santos, 2000). Pesquisas mais recentes voltam-se para o estudo de aspectos da cultura escolar, analisando as práticas, os rituais e os valores presentes no seu cotidiano. Tais reflexões têm como pressuposto a concepção de que a escola é um espaço de produção de saberes e, nesse sentido, outra concepção de saber se estrutura, resultante da busca por uma racionalidade mais ampla e mais flexível, capaz de dar conta da multiplicidade e da diversidade dos saberes humanos (Tardif, 2000).
Ainda nessa perspectiva de investigação, vários estudos vêm sendo feitos sobre o tema da transformação dos saberes científicos em saberes escolares. No campo da didática da matemática, Chevallard (1991, p. 214) indica que "Os processos transpositivos - didáticos e, mais genericamente, institucionais são, imagina-se, a mola essencial da vida dos saberes, de sua disseminação e de sua funcionalidade adequada”. Para esse autor, a manipulação transpositiva dos saberes é condição sine qua non para o funcionamento das sociedades. Na sua visão, as transformações que os saberes sofrem no âmbito do ensino são fundamentais, e a valorização da pura produção de conhecimento, em detrimento das manipulações necessárias que ocorrem no processo de socialização, sugere a impossibilidade do próprio funcionamento das sociedades.

Considera-se assim, com base nos elementos mencionados, que a transformação do conhecimento científico com fins de ensino e divulgação não constitui simples "adaptação" ou mera "simplificação" de conhecimento, podendo ser então analisada na pers- 
pectiva de compreender a produção de novos saberes nesses processos.

Com base nesse pressuposto, o trabalho que aqui se apresenta buscou estudar como ocorre o processo de transposição didática e de recontextualização nos espaços de museus de ciências, procurando entender os mecanismos de constituição do conhecimento que está expresso nas exposições que abordam temáticas biológicas. Para isso, tomou-se por base referenciais teóricos advindos do campo da educação, já que nessa área têm sido acumuladas pesquisas que entendem a escola não como uma mera reprodutora do conhecimento científico, mas como um espaço diferenciado de produção de saberes. Procurando trazer esse debate para o espaço dos museus, foram aprofundados os estudos no campo da museologia e da comunicação que pudessem auxiliar na compreensão das especificidades que esse local em particular impõe a esse processo de produção. Assim, entende-se que o museu, no que se refere à sua dimensão educativa, é também um local de produção de saberes próprios.

A pesquisa realizada teve como universo cinco exposições de museus no campo da biologia. A abordagem metodológica foi qualitativa e foram feitas entrevistas com os coordenadores e/ou elaboradores das exposições, uma observação dessas exposições e uma análise documental. Com base nos dados, vários aspectos foram analisados. Este texto discute particularmente o processo de construção do referencial teórico utilizado na pesquisa, já que por uma escolha fundamentada no conceito de transposição didática/museográfica (Chevallard, 1991; Simonneaux \& Jacobi, 1997) optou-se - a partir das críticas e dos limites percebidos no uso deste conceito - pela ampliação desse referencial. Desse modo, a análise da constituição do discurso expositivo acabou por assumir como principal suporte teórico o conceito de recontextualização de Bernstein (1996a), com base em sua análise do discurso pedagógico. Considera-se importante essa discussão na medida em que levanta limites e possibilidades do conceito de transposição didática - tão largamente utilizado no campo do ensino de ciências e matemática - e analisa os desafios de trabalhar com a concepção de discurso pedagógico de Bernstein para o estudo dos processos educativos nos espaços de museus de ciências. Desse modo, aspectos relativos à construção do discurso expositivo estudado na pesquisa também serão esboçados aqui.

Para realizar a análise aqui pretendida, iniciouse com a apresentação dos conceitos de transposição didática e de recontextualização, buscando aprofundálos e discutindo suas limitações. Ao final, foi intenção problematizar o uso de tais conceitos para o estudo da produção do discurso expositivo nos museus de ciências, a partir de elementos fornecidos pela análise dos dados da investigação realizada.

\section{A transposição didática: origem e conceitualização}

Neste item é intenção apresentar, de forma sucinta, alguns elementos relacionados à teoria ${ }^{1}$ da transposição didática, dando destaque aos seus aspectos essenciais. Os estudos sobre transposição didática têm em Yves Chevallard a principal referência. Segundo Astolfi e Develay (1990), a teoria da transposição didática teve origem ${ }^{2}$ na didática das matemáticas, através do trabalho de Chevallard e Joshua, autores que estudaram a matemática do conceito de distância e analisaram as transformações sofridas por esse conceito, desde a sua produção, no "saber sábio", até sua introdução nos programas de geometria na sétima série; ou seja, analisaram as modificações de seu estatuto teórico pelos círculos de pensamento intermediários entre a pesquisa e o ensino. Tendo por base a idéia de que o saber científico sofre um processo de

\footnotetext{
${ }^{1}$ Alguns autores, como Raisky e Caillot (1996), referem-se
} a esse conceito utilizando o termo "teoria", sem, contudo, apoiála. Neste texto irei me referir à transposição didática como conceito e como teoria.

${ }^{2}$ Forquin (1992, p. 33) cita trabalho de Michel Verret, de 1975, que já falava em uma transformação de um objeto em objeto de ensino. 
transformação ao se tornar conhecimento ensinável no espaço escolar, propõe-se a existência de uma "epistemologia escolar que pode ser distinguida da epistemologia em vigor nos saberes de referência" (Astolfi \& Develay, 1990, p. 48).

Chevallard (1991), em seu livro La transposición didáctica: del saber sabio al saber enseñado, parte do pressuposto de que o ensino de um determinado elemento do saber só será possível se esse elemento sofrer certas "deformações" para que esteja apto a ser ensinado. Nesse aspecto, indica elementos que caracterizam o funcionamento didático com base no conceito de transposição didática, sendo que o saber ensinado supõe processos de:

- descontemporalização: o saber ensinado é exilado de sua origem e separado de sua produção histórica na esfera do saber sábio;

- naturalização: o saber ensinado possui o incontestável poder das “coisas naturais", no sentido de uma natureza dada, sobre a qual a escola agora espera sua jurisdição;

- descontextualização: existe algo invariante (significante) e algo variável no elemento do saber sábio correspondente ao elemento do saber ensinado e, nesse sentido, procede-se através de uma descontextualização dos significantes, seguida de uma recontextualização em um discurso diferente (até aqui, trata-se de um processo comum e fácil de ser identificado). No entanto, nesse processo, há algo que permanece descontextualizado, já que não se identifica com o texto do saber, com a rede de problemáticas e de problemas no qual o elemento descontextualizado encontrava-se originalmente, modificando dessa forma seu emprego, ou seja, seu sentido original;

- despersonalização: o saber considerado em statu nascendi está vinculado a seu produtor e se encarna nele. Ao ser compartilhado na academia, ocorre um certo grau de despersonalização comum ao processo de produção social do conhecimento, que é requisito para sua pu- blicidade. Porém, esse processo é muito mais completo no momento do ensino, pois cumprirá uma função de reprodução e representação do saber sem estar submetido às mesmas exigências da produtividade.

No sistema didático - formado pelo saber ensinado professor-aluno - há, para Chevallard (1991), uma profunda relação entre os elementos internos e externos que o influenciam. Esse sistema didático estaria inserido na noosfera, que, por sua vez, se coloca no interior do "entorno", ou seja, na sociedade. O conceito de noosfera é central para o entendimento da transposição didática. É onde se opera a interação entre o sistema de ensino stricto sensu e o entorno societal; onde se encontram aqueles que ocupam postos principais do funcionamento didático e se enfrentam com os problemas resultantes do confronto com a sociedade; onde se desenrolam os conflitos, se levam a cabo as negociações; onde se amadurecem soluções; local de atividade ordinária; esfera de onde se pensa.

Para explicar como ocorrem os fluxos do saber que vão desde o entorno até o sistema de ensino, passando pela noosfera, e que garantem a possibilidade de ensino, Chevallard afirma a importância da compatibilização entre esse sistema e seu entorno. Segundo ele, o saber ensinado envelhece biologicamente e moralmente, aproximando-se do senso comum e se afastando do saber sábio (banalização e deslegitimização). Entretanto, a introdução de determinados conceitos do saber sábio no saber ensinado se dá por necessidade da manutenção do próprio sistema, dandolhe novamente legitimidade, principalmente perante os pais.

Há, porém, ainda, uma outra dimensão analisada pelo autor, que corresponde ao ponto de vista do aluno. Para fins de aprendizagem, modifica-se o saber, e isso pode ser feito de uma forma simplista de transposição didática - suprimindo a dificuldade quando ela aparece - ou através de uma reorganização do saber, de uma verdadeira refundação dos conjuntos de conteúdos. Esse trabalho que a noosfera realiza para ela- 
borar um novo texto do saber se consagra como uma estratégia de ataque às dificuldades de aprendizagem, através de sua identificação. Nesse movimento de compatibilização que a noosfera realiza ocorre a construção de um novo texto, em busca da organização de um bom ensino. No entanto, sabe-se que, antes de ser bom, um ensino deve ser possível e, nesse sentido, a noosfera acaba somente por considerar alguns elementos referentes às condições didáticas, deixando muitos outros escaparem: "Quando os programas são preparados começa um outro trabalho: é a transposição didática interna" (Chevallard, 1991, p. 44).

Dessa forma, para Chevallard, os conteúdos de saber designados como aqueles a ensinar são verdadeiras criações didáticas, suscitadas pelas necessidades do ensino. Esse trabalho de transformação de um objeto de saber em um objeto de ensino é o que ele chama de transposição didática.

No posfácio da segunda edição de seu livro, Chevallard discute, de maneira enfática, algumas críticas feitas à teoria da transposição didática. A seu ver, o que caracteriza os saberes é sua característica de "multilocação", ou seja, o fato de que

[...] um saber dado S se encontra em diversos tipos de instituição I, que são para ele, em termos de ecologia dos saberes, respectivos habitats diferentes. Desse modo o saber ocupa regularmente nichos muito diferentes, logo as relações entre os saberes e as instituições também são diversas. Correlativamente, a maneira que os agentes da instituição vão “manipular” esse saber será variável. (1991, p. 153)

Há, assim, quatro formas de manipulação dos saberes: uma instituição pode utilizar um saber, pode também ensinar, ou ainda produzi-lo. O quarto tipo de manipulação seria a transpositiva.

$\mathrm{O}$ autor também discute a legitimidade das práticas sociais enquanto saberes e, em linhas gerais, assume uma posição que diferencia saberes de práticas sociais. Para ele, o conceito de saber diz respeito ao corpo de conhecimento que é legitimado epistemologicamente, legitimação esta que se sobrepõe, geralmente, à legitimação cultural. Nesse sentido, o cará- ter acadêmico ou semi-acadêmico do saber é condição crucial para a ecologia didática. Em sua visão, um saber sábio não pode se autoproclamar um saber, muito menos a escola pode autorizar a si mesma, e menos ainda os docentes: "O que ocorre na Escola depende, portanto eminentemente da legitimidade que a sociedade lhe concede e lhe nega" (idem, p. 164).

A origem dos saberes, segundo Chevallard, pode dar-se nas práticas sociais; no entanto, nem todo saber chega a ser legitimado e alcança o status de saber sábio. A seu ver, existe uma distância entre um saber e uma prática, e o saber sobre o domínio de uma prática não se constitui necessariamente em um saber dessa prática. Para o autor, então, os saberes das práticas sociais só serão considerados efetivamente $s a$ beres a partir de sua legitimação cultural, mas principalmente da legitimação epistemológica.

Os pontos levantados constituem alguns dos alicerces da teoria da transposição didática. Ainda antes de apresentar o debate em torno deles, destacamse outros trabalhos importantes que abordam essa temática.

\section{A transposição didática e a transposição museográfica: outras apropriações da teoria}

Vários são os autores que têm trabalhado com o conceito de transposição didática na literatura internacional e nacional. Indicou-se aqui aqueles considerados relevantes para as reflexões deste artigo.

Um dos trabalhos que mais divulgou o conceito de transposição didática entre os pesquisadores de ensino das ciências no Brasil foi o livro A didática das ciências, de Astolfi e Develay (1990). Nesse livro, os autores propõem uma reflexão epistemológica: a) que examine a estrutura do saber ensinado, b) que esteja atenta aos aspectos históricos das ciências, baseada na idéia de ruptura e obstáculo e c) que promova a relação entre epistemologia e didática. Sobre o tema da transposição didática, esses autores defendem a existência de uma epistemologia escolar, já que afirmam que na escola o saber sábio sofre uma mudança em seu estatuto epistemológico e, dessa forma, o que se 
ensina nela não seriam saberes em estado puro, mas sim conteúdos de ensino. Astolfi e Develay, nessa obra, propõem a sistematização da transposição didática, afirmando, porém, que, além dela, outros determinantes pesam sobre a elaboração curricular. São eles as práticas sociais de referência, os níveis de formulação de um conceito (nos planos lingüístico, psicogenético e epistemológico) e as tramas conceituais.

Em artigo publicado anteriormente ao livro citado, Develay (1987) apresenta sua pesquisa sobre a transposição didática em ciências biológicas. Ao trabalhar com o conceito de memória, questiona o processo de escolha do que seria a referência para o estabelecimento do saber sábio. Afirma assim que o saber sábio não é um produto de um indivíduo isolado, mas de equipes alocadas em diferentes laboratórios, ou fruto de discussão em congressos e simpósios. Também acentua o fato de que a transposição didática varia de acordo com os diferentes níveis de ensino, havendo várias etapas de transposição de saberes. ${ }^{3}$

Quanto ao fato de se tratar de um estudo sobre um conceito pertencente às ciências biológicas, Develay (1987) tece algumas considerações importantes para a nossa discussão. Indica que a transposição didática na área da biologia conduz a uma série de transformações já destacadas por Chevallard, mas também a um processo de dogmatização, que pode ser explicado por três razões: a primeira, sociopolítica, relativa à visão neutra e universal que a ciência assume em nossa sociedade; a segunda, institucional, relacionada aos processos de transposição que ocorrem na noosfera, os quais são determinados pelas instituições e pelos atores envolvidos na seleção dos conteúdos; e, por fim, a epistemológica, que diz respeito às especificidades relacionadas à complexidade e à noção de causa nas ciências biológicas.

${ }^{3}$ Nesse aspecto, Develay (1987) opta, em seu trabalho, pelo estudo da transposição didática em livros didáticos de diferentes séries, mas que foram publicados no mesmo ano do manual científico utilizado por ele como referência do conceito de memória no saber sábio.
Tanto nesse artigo de Develay como no livro de Astolfi e Develay, os autores sublinham as influências políticas e sociais e destacam os aportes oriundos das práticas sociais, os quais, além do saber sábio, constituem referências importantes para a transposição didática. Ao fazer esse destaque, colocam-se de forma diferenciada de Chevallard quanto ao papel das práticas sociais na produção do saber escolar. Além disso, para Develay o conceito de transposição didática, mais do que promover uma modificação semiótica do discurso, promove uma modificação epistemológica, o que determina a existência de uma epistemologia escolar própria. Assim, ao destacar os aspectos epistemológicos envolvidos na transposição didática, os quais seriam particulares na biologia, o trabalho de Develay nos ajuda a problematizar a definição de saber sábio enquanto saber único e hegemônico, que orientaria sozinho a produção do saber escolar. $\mathrm{O}$ âmbito do saber sábio, com Develay, revela sua complexidade.

Ao discutir o processo de transposição didática no contexto brasileiro, Lopes (1997) questiona o uso do termo transposição didática e propõe, em substituição, a expressão mediação didática. Afirma também que, no caso das ciências físicas, esses processos de mediação didática voltados para a aproximação com o senso comum se realizam, normalmente, pela construção de metáforas e analogias na ciência e no ensino de ciências, elementos que têm sido objeto de estudo nas pesquisas dessa área.

Essa autora discute ainda o que chama de uma "contradição do conhecimento escolar" que, ao mesmo tempo, produz configurações cognitivas próprias e socializa o conhecimento científico. Sinaliza então para duas posições distintas e questionáveis a que essa contradição pode levar: uma delas é que a escola não tem como superar essa contradição, pois o conhecimento científico em si apresenta uma dificuldade que só é superável pela via da simplificação e, por conseguinte, da distorção de conceitos, cabendo apenas às instituições eminentemente produtoras de conhecimento o trabalho de veiculação do mesmo de forma correta; a outra consiste em que a única forma de su- 
perar essa contradição é resgatar na escola o seu papel de transmissora/reprodutora de conhecimentos produzidos em outras instâncias, procurando estabelecer a correspondência entre conhecimento escolar e conhecimento científico. Colocando-se contra ambas as posições, para a autora o conhecimento escolar é um tipo de conhecimento próprio que se caracteriza por ser uma (re)construção do conhecimento científico: a didatização não é meramente um processo de vulgarização ou adaptação de um conhecimento produzido em outras instâncias (universidades e centros de pesquisa). A seu ver, o trabalho de didatização acaba por implicar, necessariamente, uma atividade de produção original e, por conseguinte, deve-se "recusar a imagem passiva da escola como receptáculo de subprodutos culturais da sociedade. Ao contrário, devemos resgatar e salientar o papel da escola como socializadora/produtora de conhecimentos" (Lopes, 1997, p. 231).

Cicillini (1997), ao estudar a produção do conhecimento biológico no contexto da cultura escolar sobre o tema da teoria da evolução, em escolas públicas de ensino médio brasileiras, analisou o processo de seleção de conteúdos, percebendo as formas de inclusão e exclusão destes no sistema de ensino. Em linhas gerais, conclui que o ensino de biologia oferecido é fragmentado, impregnado de conotações ideológicas, o que foi verificado pela exclusão de partes do conhecimento evolutivo, pela forma de apresentação deste para os alunos e pelas características da linguagem dos professores. As conclusões de seu trabalho assemelham-se às de Develay no que se refere à dogmatização que o conhecimento biológico pode sofrer no ensino. Propõe, nesse aspecto, a necessidade de uma maior aproximação entre conhecimento escolar e científico.

Mais recentemente, no contexto brasileiro, Lima (2002) analisou a transposição didática do conceito de teia alimentar na esfera acadêmica e em livros didáticos do ensino fundamental. Sua metodologia foi elaborada a partir da criação de nove categorias para análise do processo de transposição: dimensão ontológica do conceito, atualização em relação à pesquisa científica, dimensão epistemológica subjacente à linguagem, perspectiva histórica, presença de controvérsias científicas, relação com a temática ambiental/ movimentos ambientalistas, imagens do livro, linha da ecologia e exercícios propostos. Para realizar tal análise, Lima definiu duas perspectivas para o conceito - a científica (recente e presente nas publicações em periódicos científicos e livros voltados para a pós-graduação) e a acadêmica (livros-texto de ecologia geralmente usados por autores de livros didáticos). Uma de suas conclusões refere-se à desatualização do conceito de teia alimentar na passagem da esfera científica para a acadêmica. Quanto à análise dos livros didáticos, a autora revela a ocorrência de falhas e equívocos de diversas naturezas, apontando para a necessidade de mais estudos que auxiliem na definição de critérios para o processo de transposição didática.

Rovira e Sanmartí (1998), pesquisadoras espanholas, afirmam que os conceitos e os modelos teóricos da ciência, para serem utilizados em aula, devem ser reconstruídos por um processo de transposição didática. Para elas, existiria uma "ciência escolar" que não é uma simples redução ou simplificação da ciência dos cientistas; é, sim, "uma reconstrução que deve cumprir a condição de selecionar aspectos fundamentais de cada teoria ou modelo e, ao mesmo tempo, devem ser relevantes e úteis para os alunos na elaboração de explicações significativas acerca dos fenômenos naturais" (Rovíra \& Sanmartí, 1998, p.1). De acordo com as autoras, é possível chegar a melhores resultados nesse processo se o ponto de partida for o "de uma boa seleção de conceitos e uma idônea transposição didática, que possibilite um bom processo de construção de modelos teóricos ao longo da escolaridade", o que exige inovar em relação às estratégias de ensino e de planejamento de instrumentos facilitadores de aprendizagem (idem, p. 20).

A partir da apresentação desses trabalhos sobre o tema da transposição didática e da produção de conhecimento escolar, alguns pontos podem ser ressaltados. Em síntese, esses trabalhos apontam para a idéia de que existe uma cultura escolar sui generis, resul- 
tante de seleções feitas a partir da cultura mais ampla (Forquin, 1992). Na escola, ocorre uma reconstrução e/ou uma nova produção de conhecimento, existindo mesmo uma "ciência escolar", com uma epistemologia própria. Há, porém, diferentes perspectivas nessa literatura, no que se refere à "distância" necessária e tolerável entre o conhecimento escolar e o científico. Para alguns, deve-se promover uma aproximação entre ambos, enquanto para outros tal distância constitui espaço de produção de conhecimento escolar.

No âmbito da educação em museus, a questão da transposição do saber científico também vem orientando práticas e sendo tema de pesquisa (Asensio \& Pol, 1999; Simonneaux \& Jacobi, 1997; Allard et al., 1996). Tomando por referência o trabalho de Chevallard (1991) e seu conceito de transposição didática, afirma-se que a ciência não é apresentada nos museus em seu estado puro, destacando-se os processos de transformação que o conhecimento científico sofre ao ser exposto nesses locais.

Ao estudar a linguagem presente na produção de pôsteres numa exposição científica, o trabalho de Simonneaux e Jacobi (1997) propõe a noção de transposição museográfica, caracterizada como uma operação delicada de transformação, na qual elementos como espaço, linguagem, conceitos e texto estão em jogo. Além disso, Asensio e Pol (1999) discutem a importância atual dos museus em comunicar mais e melhores mensagens entre pessoas, grupos e culturas, o que torna fundamental a realização de estudos sobre a eficácia da mediação comunicativa das coleções no âmbito específico dos museus e das exposições. Para tal, os autores discutem os fundamentos da transposição expositiva, afirmando ser um processo muito complexo o da adequação de um saber científico para sua exposição em um museu, objetivando a recepção pelo público. Para eles, várias considerações devem ser realizadas para que as variáveis que influenciam esse processo tenham um mínimo de êxito. Nessa perspectiva, Asensio e Pol propõem que, para a adequação e comunicabilidade desse saber em situações de ensino ou de exposição, deve-se ter por base cinco fontes fundamentais de reflexão: a socio- cultural, a disciplinar, a psicológica, a didática e a museológica.

É possível assim perceber, por um lado, o impacto do conceito de transposição didática na produção científica no campo educacional, seja formal ou não-formal, como no caso dos museus. No entanto, é possível também apontar os desafios na realização do que poderia ser chamado de uma "boa transposição didática" ao se produzir conhecimentos escolares e museais. Que distância os conceitos, as idéias e os fenômenos científicos apresentados no ensino e na divulgação devem ter do âmbito em que foram produzidos? Serão os objetivos da ciência iguais àqueles do ensino de ciências? Que outros saberes fazem parte do processo de produção do saber educacional?

\section{As críticas à transposição didática}

Como foi visto, a noção de transposição didática vem ganhando cada vez mais espaço nos debates na área educacional, ${ }^{4}$ especialmente na didática das ciências. Em contraposição, críticas foram formuladas, como aquelas propostas por Caillot (1996), que discute a validade e a amplitude da teoria da transposição didática. Situando a origem do conceito, esse autor afirma que, para Chevallard, "a referência de um conteúdo de ensino e o que o legitima é o saber sábio elaborado pela comunidade de pesquisadores" (p. 20). Dessa forma, a teoria da transposição didática definida por Chevallard seria uma teoria que, de acordo com

${ }^{4}$ Por exemplo, o parecer número CNE/CP 009/2001 do Conselho Nacional de Educação, aprovado 8/5/2001 sobre as "Diretrizes Curriculares Nacionais para a Formação de Professores da Educação Básica, em nível superior, curso de licenciatura, de graduação plena", afirma que: "Sem a mediação da transposição didática, a aprendizagem e a aplicação de estratégias e procedimentos de ensino tornam-se abstratas, dissociando teoria e prática. Essa aprendizagem é imprescindível para que, no futuro, o professor seja capaz tanto de selecionar conteúdos como de eleger as estratégias mais adequadas para a aprendizagem dos alunos, considerando sua diversidade e as diferentes faixas etárias”. 
Caillot, deveria evoluir e, por essa razão, possuir um poder explicativo universal, devendo ser aplicado a todos os saberes transmitidos pela escola. E é exatamente nesse aspecto que esse autor elabora sua posição contrária.

Na visão de Caillot, com base em trabalhos como os de Martinand, publicados em 1982 e 1986, a teoria da transposição didática é problemática, já que Chevallard parte do pressuposto que existe um saber que é único, não considerando que a produção de um programa novo é uma produção social de diferentes atores em jogo, que por sua vez vão compor a noosfera. Desse modo, para Caillot, "a teoria da transposição didática, como foi formulada por Chevallard, teria então um domínio de validade limitado, que seria aquele das matemáticas. Outras referências além do saber sábio deverão ser levadas em conta na definição de conteúdos de ensino" (1996, p. 23). ${ }^{5}$ Defende então que o saber sábio não seria a única referência do saber ensinado, considerando assim que existem saberes ligados às práticas sociais que não pertencem forçosamente ao saber acadêmico elaborado pela comunidade científica. ${ }^{6}$

Dessa forma, afirma Caillot que o conceito de transposição didática forjado por Chevallard é discutível e mesmo contestável, já que, a seu ver, na forma pela qual foi inicialmente elaborado, ele é muito ligado ao contexto da matemática e de seu ensino, sendo talvez adaptado a um tipo particular de epistemolo-

${ }^{5}$ É interessante perceber que Astolfi e Develay (1990) também defendem a necessidade de considerar as práticas sociais na elaboração do currículo escolar, baseados no mesmo autor utilizado por Caillot, ou seja, Martinand.

${ }^{6}$ No posfácio do livro de Chevallard (1991), já citado anteriormente, o autor responde a críticas feitas à transposição didática, sem, no entanto, mencionar seus autores. Uma das críticas que Chevallard rebate é exatamente a perspectiva apontada por Caillot, referente à participação das práticas sociais na constituição do saber escolar. Como foi visto, para Chevallard, saberes e práticas sociais não podem ser confundidos, e para que as práticas se tornem saberes devem ser legitimadas epistemologicamente, e não só culturalmente. gia. Contudo, para outras disciplinas de referência, como a química, ou línguas, em que a finalidade é outra, a teoria da transposição didática seria insuficiente: "É uma teoria de domínio de validade limitado, como numerosas teorias. Ela é então dificilmente transponível, nesse estado, para outras disciplinas escolares" (idem, p. 34).

As críticas feitas por Caillot à teoria da transposição didática podem assim ser sintetizadas em alguns aspectos. Em primeiro lugar, ele reivindica o espaço dos saberes das práticas sociais como referências tão legítimas quanto o saber científico ou sábio para a constituição do saber escolar. Em segundo lugar, discute a possibilidade de se transpor essa teoria para outros campos do conhecimento além das matemáticas. Nesse aspecto, Caillot traz para o debate a complexidade e a particularidade do processo de construção do saber científico nas diferentes áreas do conhecimento. Essa especificidade não pode ser generalizada para as diferentes áreas do conhecimento, já que cada uma tem uma história particular de construção, uma epistemologia própria. Além disso, esta história não é linear e implica diferentes perspectivas em conflito, sendo também influenciada, em algumas áreas, por elementos externos à produção do conhecimento stricto sensu. Os saberes científicos, dessa forma, seriam plurais.

Pode-se assim afirmar que o cerne do debate entre a perspectiva de Chevallard e a de Caillot está na compreensão do que seria considerado saber sábio e do papel e da legitimidade das práticas sociais na constituição do saber escolar. Esses aspectos foram também destacados por Develay (1987) e Astolfi e Develay (1990).

O referencial teórico da transposição didática/ museográfica ajuda a perceber que, na socialização do saber científico, este se constitui como um dos elementos que fazem parte da construção do saber escolar/museal. Mas ele não é o único, pois outros saberes também participam da constituição do saber educacional; o mesmo valendo para os museus: na elaboração das exposições, outros elementos entram no jogo de constituição do saber exposto. Essas considerações tomam por referência não só as críticas ao conceito de 
transposição didática, mas também os dados obtidos na pesquisa em que se baseia este trabalho.

Durante a realização desta investigação, de uma perspectiva inicial preocupada em analisar as transformações que o conhecimento biológico sofria ao ser apresentado nas exposições, foi-se delineando insistentemente a presença de outros saberes, que não apenas aquele biológico, na produção do discurso expositivo. Desse modo, na medida em que outros aspectos, relacionados a outros campos do conhecimento e a práticas distintas, se faziam presentes e tomavam parte nas decisões sobre o que e o como expor, o referencial teórico da transposição museográfica parecia apresentar limites para a compreensão desse processo. Verificou-se, na pesquisa, que elementos como a prática museológica, ${ }^{7}$ as características das coleções, a história dos museus de ciências e de cada instituição em particular, a formação profissional da equipe envolvida, entre outros aspectos, também participavam das decisões sobre a elaboração das exposições. Percebeu-se assim que a transformação dos signos, dos sinais, da linguagem e dos objetos estava também submetida a outros discursos, que não somente o da ciência.

Nesse momento, o foco da tese se direcionou para a compreensão desses elementos, havendo a necessidade de buscar outros referenciais que pudessem auxiliar na compreensão do processo de transformação do saber científico na elaboração das exposições.

\section{A recontextualização como referencial}

Na perspectiva de trabalhar com referenciais teóricos que pudessem melhor explicar o processo de produção do discurso expositivo nos museus, utilizou-se o trabalho de Bernstein (1996a, 1996b), que analisam a estruturação social do discurso pedagógico e das formas de sua transmissão e aquisição. Afir-

${ }^{7}$ Prática que articula a conservação da materialidade dos objetos, a documentação das respectivas informações, a elaboração de discursos expositivos e a implementação de estratégias educativas e de ação cultural (Bruno, 1998). ma o autor que "o discurso pedagógico é um princípio para apropriar outros discursos e colocá-los numa relação mútua especial, com vistas à sua transmissão e aquisição seletivas” (1996a, p. 259). Para ele, o discurso pedagógico é "um princípio que tira (desloca) um discurso de sua prática e contexto" (idem, ibidem), recolocando aquele discurso de acordo com seu próprio princípio de focalização.

A constituição do discurso pedagógico ocorre com base em regras específicas. Segundo Bernstein (1996a), as regras distributivas são aquelas pelas quais o dispositivo pedagógico controla a relação entre poder, conhecimento, formas de consciência e prática no nível da produção do conhecimento. Elas marcam e distribuem quem pode transmitir o quê, a quem e sob que condições, e assim tentam estabelecer limites interiores e exteriores ao discurso legítimo.

No que se refere às regras recontextualizadoras, o autor entende que o discurso pedagógico pode ser definido como as regras para embutir e relacionar dois discursos e, nesse processo de relação, o discurso da competência, instrucional, é embutido no discurso regulativo, de ordem social. O princípio recontextualizador do discurso pedagógico age de forma seletiva, apropriando, refocalizando e relacionando outros discursos a partir de sua própria ordem, tornando-os um outro discurso.

Quanto às regras de avaliação, o autor afirma que a chave da prática pedagógica é a avaliação contínua, e esta se encontra na relação entre a aquisição e a transmissão do conhecimento. Assim, as regras distributivas estariam relacionadas com a produção do discurso, as regras recontextualizadoras, com a transmissão, e as regras de avaliação, com a aquisição.

O referencial teórico de Bernstein, especialmente seu conceito de recontextualização, guarda proximidade com o conceito de transposição didática de Chevallard. Esse fato vem sendo apontado na literatura $^{8}$ e, como exemplo, citamos o trabalho de Gvirtz e Palamidessi (1998) que utiliza ambos os conceitos

${ }^{8}$ No GT de Sociologia da Educação da ANPEd, em 2002, o tema da aproximação entre os conceitos de transposição didática 
para discutir a questão da transformação do conhecimento científico na escola, sem, entretanto, problematizar as diferenças entre eles. Considero que tais conceitos, apesar de próximos, possuem estruturas históricas e epistemológicas diferenciadas.

Chevallard (1991) ancora seu trabalho nos estudos da didática da matemática. Para ele, o saber sábio, ao se transformar em saber ensinado, é descontextualizado, naturalizado, despersonalizado e descontemporalizado; nesse sentido, considera o saber científico como referência principal para o saber ensinado, apesar de afirmar a necessidade de sua adaptação. Em uma perspectiva diferente, Bernstein (1996a, 1996b), na área da sociologia da educação, propõe o conceito de recontextualização com base na sua teoria sobre o discurso pedagógico. Esse conceito deve ser visto dentro de um quadro teórico mais amplo, de críticas e de debate em torno das teorias de reprodução, já que focaliza essencialmente a forma, as regras e os princípios de produção e reprodução do discurso pedagógico.

Para Bernstein (1996a, p. 258), o discurso pedagógico relativo a toda prática de instrução é um discurso recontextualizador. Trata-se assim de uma regra que embute um discurso de competência (o que poderíamos chamar do saber sábio de Chevallard) num discurso de ordem social, de uma forma tal que o último sempre domina o primeiro: o discurso instrucional - que transmite as competências especializadas - é embutido no discurso regulativo - que cria a ordem, a relação e a identidade especializada no discurso instrucional, sendo este último predominante.

Nesse sentido, por um lado, os conceitos de transposição didática e de recontextualização se aproximam, pois dizem respeito às transformações que o saber sábio ou o discurso científico sofrem ao passar para os contextos de ensino. Contudo, na teoria da

e recontextualização foi abordado durante a discussão de trabalhos que tinham Basil Bernstein como referencial teórico. Nas discussões, ficou patente a necessidade de aprofundar as proximidades e distâncias entre eles. transposição didática, o foco de análise é a transposição dos conceitos científicos no processo de ensino, tendo por referência ainda o saber sábio. $\mathrm{O}$ saber a ser ensinado, para Chevallard, é legitimado epistemologicamente, e a legitimação social está submetida à legitimação epistemológica.

Já na perspectiva da recontextualização, o foco é estudar a transferência dos textos entre diferentes contextos de produção e reprodução, mediada pelas relações de poder e pela regulação do discurso de ordem social: há aqui a produção de um discurso com características de discurso recontextualizador, o discurso pedagógico, sendo que o discurso regulativo se sobrepõe ao instrucional.

Desse modo, uma das principais diferenças entre a transposição didática e a recontextualização, a meu ver, está na compreensão do papel da "ordem social" na transformação do conhecimento científico e na produção do saber a ser ensinado e do discurso pedagógico. Para Chevallard, a legitimação acadêmica se sobrepõe à social. Para Bernstein, o discurso regulativo - de ordem social - é o legitimador.

A partir da noção de noosfera, Chevallard considera os diferentes atores e instituições que participam da seleção dos objetos de ensino, mas afirma que nem a escola, nem os professores, nem os alunos podem legitimar o saber a ser ensinado, papel das instâncias acadêmicas de produção do conhecimento. $\mathrm{O}$ autor não problematiza as relações de poder presentes na noosfera, sendo sua teoria fundamentada em pressupostos epistemológicos.

O trabalho de Bernstein apresenta o processo de constituição do discurso pedagógico, dando ênfase ao papel do discurso de ordem social na seleção, no seqüenciamento e no compassamento da aquisição, já que as regras que determinam as formas como essas ocorrem derivam não da lógica interna da disciplina, mas sim de fatores sociais.

Em meu trabalho em museus de ciências, entendo que as exposições são unidades pedagógicas. No campo da museologia, um dos procedimentos inerentes à prática museológica é o da elaboração de "discursos expositivos". Desse modo, desenvolvo a hipó- 
tese de que o discurso expositivo pode ser compreendido com base em uma analogia com o discurso pedagógico de Bernstein. Acredito ser rica e importante a utilização desse referencial teórico para compreender os processos de constituição do discurso expositivo e os mecanismos de recontextualização que ocorrem na produção do conhecimento nas exposições e nas demais atividades educativas desenvolvidas nos museus de ciências. No entanto, essa analogia se mostrou limitada em alguns aspectos, como será explicitado a seguir.

\section{O jogo de constituição do discurso expositivo}

Um dos objetivos da pesquisa aqui em discussão foi a caracterização do discurso expositivo no processo de elaboração das exposições. Tomando como referencial o conceito de recontextualização proposto por Bernstein (1996a), percebeu-se que, no processo de constituição desse discurso, outros discursos e outras práticas sociais estão presentes e entram no jogo de relação entre eles. A forma pela qual estes discursos se relacionam para a constituição do discurso expositivo depende diretamente de elementos como: a) a história da instituição "museu" e de cada instituição estudada em particular; b) as concepções científicas, museológicas, comunicacionais e educacionais envolvidas na elaboração das exposições logo, a formação das equipes responsáveis também é fator relevante; c) a história dos acervos e coleções; e d) os tipos de objetos expostos, além de outros aspectos. Percebeu-se, desse modo, que o discurso expositivo, em certa medida, apresenta-se de forma semelhante ao discurso pedagógico, por ser capaz de recontextualizar outros discursos envolvidos no processo de sua elaboração e os recolocar a partir de seus próprios princípios e reordenamentos.

A relação que se estabelece entre os diferentes discursos - científico, museológico, educacional, comunicacional, histórico, institucional, das práticas sociais etc. - foi por mim caracterizada como um jogo. Essa denominação buscou, entre outros aspectos, a representação de que a relação entre os diferentes as- pectos se dá na realização de uma atividade fundada em regras, referentes às propostas por Bernstein (1996a) sobre o discurso pedagógico - regras distributivas, regras recontextualizadores e regras de avaliação. O jogo dos discursos também pode ser representado pela idéia de um jogo de vozes, sendo que cada área do conhecimento - sua história, sua estrutura lógica e epistemológica, seus conteúdos e métodos e os atores que a compõem - possui voz que pode ou não estar presente no produto final, no discurso expositivo. Têm voz na exposição aqueles discursos que são autorizados e legitimados, os quais são controlados pelo jogo de poder constituído social e historicamente. Há assim discursos aos quais não é dada a voz em determinadas épocas - ou que abrem mão, ou não são autorizados a participar do jogo.

Seria importante, entretanto, frisar que o jogo de relação entre os diferentes discursos não é, nem de longe, tranqüilo. Em primeiro lugar, a opção por dar voz ou não aos demais discursos para além do científico é uma decisão política e de gestão da própria instituição ou dos órgãos financiadores das exposições, das políticas governamentais de cultura e educação e dos grupos de controle. Essas decisões implicam a escolha das equipes e dos profissionais nas diferentes áreas - com seus diferentes discursos - que irão participar da elaboração e atuar na recontextualização desses discursos durante o processo de constituição do discurso expositivo. Em segundo lugar, mesmo que seja dada voz a diferentes discursos, esse espaço por si só não garante que efetivamente eles participem com o mesmo peso nas decisões, escolhas e seleções que serão realizadas durante o processo de recontextualização. Entram nesse universo de negociação fatores sociais, culturais, políticos e ideológicos que poderão regular a relação entre os diferentes discursos, dando voz a uns e calando outros. Os grupos que se encontram no poder no processo de produção do discurso expositivo é que poderão controlar essa distribuição dos discursos na elaboração das exposições.

Assim, a proximidade entre o discurso expositivo e o discurso pedagógico de Bernstein pode ser destacada. Por não ter discurso próprio, o discurso expo- 
sitivo desloca os demais discursos, incluindo o discurso da competência - o discurso científico -, embutindo-os no discurso de ordem social, regulativo, e dos valores envolvidos na produção de uma exposição.

No seu trabalho, Bernstein caracteriza o campo recontextualizador do discurso pedagógico, indicando seus atores e seu funcionamento. Analogamente, no caso dos museus, o campo recontextualizador do discurso expositivo pode ser caracterizado, pois contempla tanto as instituições oficiais que mantêm relações com os museus, como aquelas que indiretamente estão ligadas a ele. Dependendo do tipo de museu, essas instituições oficiais podem ser os órgãos do Estado - municipal, estadual ou federal - relativos à cultura, à educação, ou à ciência e tecnologia, mas também às universidades e aos institutos de pesquisa, às sociedades científicas etc. O campo também é composto pelos pesquisadores das áreas científicas, da história da ciência, da educação, da divulgação, da museologia e da comunicação, entre outros.

Bernstein faz ainda várias outras considerações sobre o campo recontextualizador do discurso pedagógico, que dizem respeito aos dados obtidos nesta pesquisa. Afirma que esse campo pode produzir subcampos especializados relativos a níveis do sistema educacional, a currículos, a grupos de alunos, que podem determinar a recontextualização independentemente do Estado. Dessa forma, a determinação de quais são os contextos de produção e reprodução do discurso pedagógico dependerá da autonomia relativa concedida aos níveis ou às agências, nos diferentes níveis do sistema educacional, sendo que a própria escola pode incluir, como parte de sua prática recontextualizadora, discursos da família, da comunidade, das relações entre os alunos, com a finalidade de tornar mais eficaz seu próprio discurso regulativo. Esses atores também podem exercer sua própria influência sobre o campo recontextualizador da escola, afetando a sua prática. Como indica o autor, a forma de regulação e a composição social dos diferentes agentes podem variar de uma situação histórica para outra; no campo pedagógico, no nível da universidade ou de instituição equivalente, aqueles que produ- zem o novo conhecimento podem ser seus próprios recontextualizadores.

No caso dos museus, como foi visto na pesquisa, dependendo do contexto histórico, da política institucional e da proposta conceitual da exposição, outros atores também podem fazer parte desse campo recontextualizador do discurso expositivo, desde os funcionários do corpo administrativo, científico e técnico do museu, até os professores e o público em geral que o visita.

Levando-se em conta essas questões, seria fundamental nesse momento discutir a relação entre o discurso expositivo e o discurso pedagógico. Considera-se assim que o discurso expositivo apresenta características bastante semelhantes ao discurso pedagógico, e, nesses termos, pode-se afirmar que o discurso expositivo possui a mesma estrutura de funcionamento do discurso pedagógico, assumindo as regras recontextualizadoras e as regras distributivas propostas por Bernstein.

No que se refere às regras avaliativas, no entanto, algumas ponderações devem ser feitas. É cada vez maior nos museus de ciências o desenvolvimento de pesquisas de público, que incluem o levantamento de perfil, de expectativas, de avaliação da exposição e da aprendizagem dos visitantes. Os resultados das pesquisas são utilizados para análise, avaliação e reformulações da exposição e/ou das ações educativas desenvolvidas nesse espaço. Geralmente, essas pesquisas procuram avaliar a efetividade dos mecanismos transpositivos e recontextualizadores dos recursos e estratégias utilizados para levar o público a compreender as narrativas propostas pela exposição e pelas ações educativas desenvolvidas no museu. Avalia-se assim a efetividade dessas atividades e a forma de interação do público com elas. Não se avalia o público, nem mesmo essa avaliação tem implicações políticas e sociais na vida do visitante, como a avaliação promovida no âmbito escolar.

Segundo Bernstein, as regras de avaliação do discurso pedagógico se relacionam com o "nível da aquisição" e, ao se desenvolverem pesquisas de público nos museus, está em jogo, de alguma forma, a "aqui- 
sição" daquilo que é exposto. Entretanto, essa dimensão não se apresenta nos mesmos termos para os alunos nas escolas e para os visitantes nos museus. Além disso, o significado de "aquisição" no âmbito dos museus ainda não está bem compreendido e constitui tema de investigação na área (Falk \& Dierking, 1992).

Dessa forma, percebe-se que o discurso expositivo possui algumas especificidades que o diferenciam de discursos pedagógicos constituídos em outros espaços educativos que não o museu. Essas especificidades se relacionam aos aspectos inerentes à instituição museu, que se diferenciam daqueles referentes à escola, por exemplo, ou de qualquer outro espaço educativo. Tais aspectos dizem respeito fundamentalmente aos elementos relativos ao tempo, ao espaço e aos objetos nos museus, mas também ao seu papel social e às implicações dessas dimensões na constituição da cultura do museu.

As dimensões temporais e espaciais são, sem dúvida, extremamente importantes no espaço escolar; entretanto, a forma de relação do indivíduo com esses elementos, nesses dois locais, é bastante diferenciada e determina maneiras diferenciadas de apropriação do discurso apresentado. A liberdade de escolha do visitante quanto aos percursos a seguir, ao que ler, ao como ler, ao que olhar, ao como olhar, ao tocar e ao que tocar (quando é dada essa opção ao público), à forma de organização das leituras, à reconstituição pessoal das narrativas propostas, ao tempo dedicado a cada elemento ou parte da exposição, à escolha de trocar ou comentar as informações oferecidas com outros visitantes levam, entre outros elementos, ao estabelecimento de uma relação espaço-temporal bastante diferenciada entre o público no museu e na escola. $\mathrm{O}$ controle sobre as implicações do domínio (ou não) desses conhecimentos também é muito distinto se compararmos esses dois locais. E, nesse sentido, existe uma relação diferenciada desses públicos com o conhecimento apresentado nesses locais.

Apesar das semelhanças entre discurso expositivo e discurso pedagógico, percebe-se que, em certa medida, existem características específicas no que se refere ao local onde o discurso pedagógico irá ser pro- duzido. A analogia aqui pretendida enfrenta limites na medida em que tanto a relação entre espaço, tempo e objeto como as implicações sociais sobre o domínio do conhecimento se dão de forma diferenciada nesses locais. Prefere-se, dessa forma, falar em comportamentos semelhantes entre os discursos pedagógico e expositivo, do que assumir a posição de que o discurso expositivo é um discurso pedagógico. Além disso, as exposições de museus podem ter outros fins que não aqueles relativos a objetivos educacionais e/ou de aprendizagem, enfatizando, por exemplo, o entretenimento e a diversão. Desse modo, postula-se que o discurso expositivo é um discurso particular que, por possuir objetivos específicos e recolocar outros discursos a partir de sua própria lógica, pode também se comportar como o discurso pedagógico.

Considero que a compreensão do processo de produção do discurso expositivo, tendo por referência os autores aqui discutidos, pode contribuir nas seleções e escolhas realizadas na elaboração de exposições de museus de ciências, especialmente naquelas em que a dimensão educativa se constitui como alicerce importante. Esse aprofundamento pode também auxiliar na construção do recente campo da divulgação científica e da educação não formal nos museus, inserido num amplo movimento social e cultural.

MARTHA MARANDINO, doutora em educação pela Universidade de São Paulo, é professora da Faculdade de Educação dessa mesma universidade. Organizou com GOUVÊA, Guaracira e LEAL, Maria Cristina. Educação e museu: a construção social do caráter educativo dos museus de ciências (Rio de Janeiro: FAPERJ \& Access, 2003); e publicou recentemente: MARANDINO, Martha. A biologia nos museus de ciências: a questão dos textos em bioexposições (Revista Ciência \& Educação, Bauru, v. 8, nº 2, 2002) e The scientific museums of the University of São Paulo, Brazil, and their search for an identity (Museology; an International Journal of Museology, Lisboa, Portugal, v. 1, nº 2, p. 53-66, 2001). Pesquisa atual: Educação não-formal em biologia: estudo sobre a práxis educativa nos museus de ciências, financiada pela FAPESP (Programa Jovem Pesquisador, 2003-2007).E-mail: marmaran@usp.br ou marmaran@unisys.com.br 


\section{Referências bibliográficas}

ALLARD, M., LAROUCHE, M.C., LEFEBVRE, B., MEUNIER, A., VADEBONCOEUR, G., (1995/1996). La visite au musée. Réseau, Canadá, p. 14-19, déc.-jan.

ASENSIO, M., POL, E., (1999). Nuevos escenarios para la interpretación del patrimonio: el desarrollo de programas públicos. Madrid: Departamento de Psicologia, Universidad Autónoma (mimeo.).

ASTOLFI, J.P., DEVELAY, M., (1990). A didática das ciências. Campinas: Papirus.

BERNSTEIN, B., (1996a). A estruturação do discurso pedagógico: classe, códigos e controle. Petrópolis: Vozes. (1996b). Pedagogy symbolic control and identity: theory, research, critique. London: Taylor and Francis.

BRUNO, M.C.O., (1998). Museologia para professores: os caminhos da educação pelo patrimônio. São Paulo: Centro Estadual de Educação Tecnológica Paula Souza - Coordenadoria de Ensino (mimeo.).

CAILLOT, M., (1996). La théorie de la transposition didactique est-elle transposable? In: RAISKY, C., CAILLOT, M. Au-delá des didactiques, le didactique. Débats autour de concepts fédérateurs. Paris/Bruxelles: De Boeck \& Larcier, p. 19-35.

CHEVALLARD, Y., (1991). La transposición didáctica: del saber sabio al saber enseñado. Buenos Aires: Aique.

CICILLINI, G.A., (1997). A produção do conhecimento biológico no contexto da cultura escolar do ensino médio: a teoria da evolução como exemplo. Tese de doutorado. Faculdade de Educação da Universidade Estadual de Campinas.

DEVELAY, M., (1987). A propos de la transposition didactique en sciences biologiques. Revue Française de Pédagogie, $\mathrm{n}^{\circ}$ 80, juillet-septembre.
FALK, J.H., DIERKING, L.D., (1992). The museum experience. Washington, DC: Whalesbak Books.

FORQUIN, J.C., (1992). Saberes escolares, imperativos didáticos e dinâmicas sociais. Teoria \& Educação, nº 5 , p. 28-49.

GVIRTZ, S., PALAMIDESSI, M., (1998). El ABC de la tarea docente: currículum y enseñanza. Buenos Aires: Aique.

LIMA, M.J.G.S., (2002). Dos saberes científicos aos saberes escolares: uma proposta metodológica para o estudo da transposição didática do conceito de teia alimentar. Dissertação de mestrado. Programa de Pós-graduação em Educação da Universidade Federal Fluminense.

LOPES, A., (1997). Conhecimento escolar em química: processo de mediação didática da ciência. Química Nova, v. 20, nº 5, p. $563-568$.

RAISKY, C., CAILLOT, M., (1996). Au-delá des didactiques, le didactique: debats autour de concepts fédérateurs. Paris/ Bruxelles: De Boeck \& Larcier.

ROVÍRA, M.P.G., SANMARTÍ, N., (1998). Las bases de orientación: un instrumento para enseñar a pensar teoricamente en biologia. Alambique - Didáctica de las Ciências Experimentales, $\mathrm{n}^{\mathrm{o}} 16$, p. 8-20, abr.

SANTOS, L.L.C.P., (2000). Pluralidade de saberes em processos educativos. In: CANDAU, V.M.F. (org.). Didática, currículo e saberes. Rio de Janeiro: DP\&A, p. 46-59.

SIMONNEAUX, L., JACOBI, D., (1997). Language constraints in producing prefiguration posters for scientific exhibition. Public Understand. Sci., v. 6, p. 383-408.

TARDIF, M., (2000). O conhecimento dos professores. Rio de Janeiro: Pontifícia Universidade Católica (mimeo.).

Recebido em novembro de 2003 Aprovado em janeiro de 2004 
José Gondra e Inára Garcia

$A$ arte de endurecer "miolos moles e cérebros brandos": a racionalidade médico-higiênica e a construção social da infância

Pensar a infância implica trabalhar com a idéia de uma vida segmentada, construir marcos de começo e término das diferentes fases, num gradiente de idades evolutivo e linear. Assim, a tentativa de especificar essas etapas termina por repartir a vida de forma detalhada, além de unificar o que se encontra recoberto em cada uma das supostas idades da vida. Unificação que não é propriedade de um passado mais recuado, pois persiste na atualidade a crença em uma infância homogênea e cronologicamente repartida. Dessa forma, a cronologia da vida, problematizada nesse trabalho, considera tanto a base, a carga e o tempo de amadurecimento biológico dos sujeitos, como as variantes culturais e a história, que também definem, de forma decisiva, as possibilidades surpreendentes do ser humano.

Palavras-chave: educação; infância; higiene

The art of hardening "soft minds and tender brains": a medicalhygienic rationality and the social construction of childhood

A reflection on childhood implies working with the idea of a segmented life, establishing initial and final limits for the different phases, in an evolving linear age scale. Thus, the attempt to specify such stages ends by dividing life up into multiple segments, in addition to unifying what remains hidden in each of the supposed ages of life. Unification is not the property of a more distant past, as the belief in a homogeneously and chronologically divided childhood persists up until now. In this way, the chronology of life discussed in this article, considers not only the base, load and time of people's biological maturation, but also the cultural differences and the history that define, in a decisive way, the surprising possibilities of the human being.

Key-words: education; childhood; hygiene

João Batista Martins

Contribuições epistemológicas da abordagem multirreferencial para a compreensão dos fenômenos educacionais

Apresenta as contribuições da abordagem multirreferencial para a compreensão dos fenômenos educacionais enfatizando os aspectos epistemológicos que ela contempla. Nesse sentido discute-se o momento histórico em que a noção de multirreferencialidade é estruturada e, em seguida, alguns conceitos utilizados que recolocam algumas questões epistemológicas inerentes ao processo de conhecimento acerca dos fenômenos sociais e, mais especificamente, aqueles concernentes à educação.

Palavras-chave: multirreferencialidade; educação; epistemologia

Epistemological contributions of the multi-referential approach to the understanding of educational phenomena

Presents the contributions of the multireferential approach to the understanding of educational phenomena emphasising the epistemological aspects. To this end, we discuss the historical moment in which the notion of multi-referentiality is structured as well as some of the concepts used to re-situate the epistemological questions inherent to the knowledge building process on social phenomena and, more specifically, those related to education.

Key-words: multi-referentiality; education; epistemology
Martha Marandino

Transposição ou recontextualização? Sobre a produção de saberes na educação em museus de ciências A transformação do conhecimento científico com fins de ensino e divulgação se constitui como espaço-tempo de produção de novos saberes. Com base nesse pressuposto, esse trabalho estudou o processo de transposição didática/museográfica e de recontextualização nos espaços de museus de ciências, procurando entender os mecanismos de constituição do discurso expresso nas exposições que abordam temáticas biológicas. Para isso, tomou-se por base referenciais teóricos advindos principalmente do campo da educação e da museologia que pudessem auxiliar na compreensão das especificidades que os museus impõem a esse processo de produção. Esse texto discute particularmente o processo de construção do referencial teórico utilizado na pesquisa, já que de uma escolha fundamentada no conceito de transposição didática/ museográfica, optou-se - com base nas críticas e nos limites do uso desse conceito - por assumir como principal suporte teórico o conceito de recontextualização. Com base nessa discussão foi intenção levantar limites e possibilidades do uso do conceito de transposição didática e analisar os desafios de trabalhar com o conceito de recontextualização para o estudo dos processos educativos nos espaços de museus de ciências.

Palavras-chave: transposição didática; recontextualização; transposição museográfica; educação em museus

Transposition or recontextualisation? On the production of knowledge in education in science museums The transformation of scientific knowledge for teaching or public communication purposes, constitutes a 
time-space for the production of new knowledge. In this study, we analyse the processes of didactical/ museographical transposition and of recontextualization in spaces at science museums, in order to understand those mechanisms, which constitute the discourse expressed in expositions dealing with biological themes. Studies carried out in the educational and museological fields were used to understand the specificity, which museums impose on this process of production. In this paper, we give special attention to the construction of the theoretical framework used in the research process. The theoretical premises that were initially used were those of the concept of didacticall museographic transposition. Based on a critique of the limits of this concept, new theoretical principles were utilised taking as their principal support the concept of recontextualization. Finally, we seek to discuss the possibilities and limits of the use of the concept of didactical/museographic transposition and analyse the challenges of working with the concept of recontextualization in order to understand those educational processes, which take place in spaces offered by science museums.

Key-words: didactical transposition; recontextualization; museographic transposition; museum education

Alice Casimiro Lopes

Políticas curriculares: continuidade ou mudança de rumos?

Com base nas análises de Stephen Ball e nos conceitos de recontextualização (Basil Bernstein) e de hibridismo (García Canclini), analisa as políticas curriculares no Governo Lula. Defende que tais políticas ainda se desenvolvem sob influência da mesma comunidade epistêmica do Governo Fernando Henrique Cardoso e aponta os princi- pais marcos de mudança que poderiam ser desenvolvidos.

Palavras-chave: hibridismo; políticas de currículo; recontextualização

Curriculum policy: continuity or change?

Analyses the curriculum policies developed by the Lula Government. It concludes by stating that they belong to the same epistemological community as those developed by the previous

Fernando Henrique Cardoso

Government. It also mentions the main possible turning points, as far as Ball's analysis of curriculum policy,

Bernstein's recontextualization and Canclini's hybridism are concerned.

Key-words: curriculum policy; hybridism; recontextualization

\section{Mériti de Souza}

Fios e furos: a trama da subjetividade e a educação

Discute a constituição da subjetividade atravessada pelo pathos e pelo logos e remetida ao singular e ao coletivo.

Essa concepção demanda a análise do excluído da identidade individualizada do homem moderno e do conhecimento como ancorado exclusivamente na razão. Considerando o trabalho desenvolvido com a população escolar e a escuta dos discursos produzidos pela alocação dessas pessoas em lugares subjetivos perante o saber, indaga-se a possibilidade da prática pedagógica constituir-se em experiência produzindo efeitos de subjetivação.

Palavras-chave: subjetividade; educação; escola; modernidade

Threads and holes: the plot of subjectivity and education

Discusses the constitution of subjectivity cut through with pathos and logos and addressed to the singular and the collective. This conception requires the analysis of that which is excluded from the individualised identity of modern man and of knowledge as anchored exclusively in reason. Based on research developed with the school population and on listening to speeches produced by these people situated in subjective places with relation to knowledge, we question the possibility of pedagogical practice constituting experience, which produces subjective effects.

Key-words: subjectivity; education; school; modernity

Maria Alice Nogueira

Favorecimento econômico e excelência escolar: um mito em questão

Na pesquisa educacional brasileira ainda carecemos de estudos sobre os processos de escolarização dos jovens originários de famílias privilegiadas do ponto de vista econômico. O presente trabalho propõe-se a incursionar, portanto, em terreno altamente lacunar, apresentando alguns resultados parciais de um estudo realizado, em 2000-2001, com 25 famílias de grandes e médios empresários(as) de Minas Gerais, cujo objetivo principal era conhecer as histórias escolares dos jovens e as estratégias educativas postas em prática por esses pais ao longo desses itinerários. Um corpus de 50 entrevistas, feitas com os jovens e suas mães, foi reunido. Suas conclusões permitem questionar a idéia corrente de que o padrão de excelência escolar é apanágio dos "ricos" ou, em outros termos, de que as elites escolares se compõem de alunos "ricos".

Palavras-chave: trajetórias escolares; estratégias educativas familiares; relação família-escola

\section{Economic privilege and school excellence}

In Brazilian educational research we still lack studies which focus on the schooling process of youngsters from families privileged from the economic point of view. This paper aims, therefore, 